\title{
Rancang Bangun Alat Pemantau Kadar pH, Suhu Dan Warna Pada Air Sungai Berbasis Mikrokontroller Arduino
}

\author{
Dhimas Abimanyu ${ }^{* 1}$, Sumarno $^{2}$, Fitri Anggraini ${ }^{3}$, Indra Gunawan $^{4}$, Iin Parlina ${ }^{5}$ \\ 1,2,3,4,5Teknik Informatika, STIKOM Tunas Bangsa Pematangsiantar, Indonesia \\ Email: $\underline{1 \text { abimanyudhimas@ gmail.com, }}, \underline{2}$ sumarno@ amiktunasbangsa.ac.id, ${ }^{3}$ ftranggraini850@ gmail.com, \\ $\underline{{ }^{4} \text { indra@amiktunasbangsa.ac.id, }}$ 5iin@amiktunasbangsa@gmail.com
}

\begin{abstract}
Abstrak
Bagi kelangsungan hidup manusia dan mahluk lainnya Air Merupakan sumber daya alam yang sangat penting. Pencemaran air khususnya air sungai sangat perlu diawasi dan perhatikan seiring semakin cepatnya proses pembangunan yang ada. Teknologi yang dapat dilakukan untuk memantau besaran kadar $\mathrm{pH}$, Suhu dan Warna yaitu sistem berbasis Mikrokontroller Arduino yang memiliki kemampuan untuk membaca dari sensor yang akan di teruskan ke LCD. Pada riset ini dikembangkan sistem pemantau kadar pH, Suhu dan Warna yang menggunakan metode mikrokontroller berbasis Arduino Uno, dimana hasilnya dapat di lihat pada layar LCD yang telah disambungkan dengan mengambil sampel dari berbagai jenis air sungai. Sensor pada tiap node di hubungkan ke Arduino Uno sebagau unit pemroses, informasi yang dibaca dari sensor di kirim ke node LCD melalui kabel jumper. Sehingga hasil-hasil pembacaan dari sensor yang ada akan menghasilkan nilai-nilai yang ada baik dari sensor $\mathrm{pH}$, sensor suhu dan sensor Warna yang akan tampil di LCD.
\end{abstract}

Kata kunci: Air Sungai, Arduino Uno, Mikrokontroller,

\section{Design And Construction Of pH Temperature And Color Monitoring Equipment In Water-Based River On Arduino Microcontroller}

\begin{abstract}
For the survival of humans and other creatures Water is a very important natural resource. Water pollution, especially river water, really needs to be monitored and paid attention to as the existing development process accelerates. The technology that can be used to monitor the amount of $\mathrm{pH}$, temperature and color levels is an Arduino microcontroller-based system that has the ability to read from the sensor which will be forwarded to the $L C D$. In this research, a monitoring system for $\mathrm{pH}$, temperature and color levels was developed using the Arduino Uno-based microcontroller method, where the results can be seen on the connected LCD screen by taking samples from various types of river water. The sensor at each node is connected to the Arduino Uno as a processing unit, the information read from the sensor is sent to the LCD node via a jumper cable. So that the readings from the existing sensors will produce existing values both from the $\mathrm{pH}$ sensor, temperature sensor and color sensor that will appear on the LCD.
\end{abstract}

Keywords: Arduino Uno, Microcontroller, The River Water,

\section{PENDAhuluan}

Teknologi informasi sangat dihandalkan, hampir di semua bidang ilmu pengetahuan ataupun pekerjaan dab aktifitas manusia dibuat kemudahan-kemudahan yang berasal dari manfaat dari teknologi yang berkembang. Namun bukan hanya sekedar itu saja tidak menutup kemungkinan penggunaan tenaga manusia nantinya tidak akan dibutuhkan kembali yang dimana tenaga kerja manusia akan beralih kepada penggunaan tenaga mesin karena dapat terjaminya kecepatan serta keakuratan dalam penggunaanya. Perguruan tinggi yang merupakan pusat perkemabngan ilmu pengetahuan selalu berusaha mengimplementasikan hasil-hasil penelitian terkhususnya bidang teknologi informasi kepada masyarakat khusnya sebagai bentuk penguatan pengetahuan, sehingga masyarakat tidak hanya berperan sebagai pengguna teknologi namun dapat berperan sebagai pelaku atas pemanfaatan teknologi tersebut. Salah satunya yaitu pemanfaatan teknologi untuk dapat mendeteksi kadar $\mathrm{pH}$ (power of Hidrogen), suhu dan warna pada air, khususnya untuk mendeteksi air sungai agar dapat di gunakan sehari-hari sesuai dengan aturan dari Menteri Kesehatan. 
Penggunaan Air sangat mendasar bagi kehidupan masyarakat, Kebutuhan air tersebut dimanfaatkan untuk konsumsi, pertanian maupun perikanan. Karena banyaknya manfaat air bagi kehidupan masyarakat, maka sangat dibutuhkan upaya-upaya dalam pengawasan terhadap kualitas air tersebutdimana salah satu sumber air yang masih tetap digunakan masyarakat yaitu penggunaan air sungai agar tetap terjaga kebersihan sehingga tidak tercemar dapat dipakai berkelanjutan,

Perubahan yang terjadi pada sebuah penampung air seperti danau, sungai, maupun air tanah yang di akibatka oleh aktifitas Manusia baik limbah Organik yang berasal dari penduduk maupun Industri merupakan sebuah Pencemaran Air. Dengan kemampuan sensor ini, maka setiap pencemaran yang ada di Air khususnya Air Sungai dapat di analisa tingkat pencemaran airnya menggunakan beberapa indikator sensor untuk mendeteksinya, seperti kadar $\mathrm{pH}$, Suhu, dan warna pada air.

Adapun dampak yang ditimbulkan dari pencemaran air ini yang sangat berbahaya yaitu dapat meracuni Sumber Air yang akan digunakan dalam kebutuhan kehidupan sehari-hari, serta dapat membuat ekosistem menjadi tidak seimbangan di air sungai. Salah satu cara sederhana dalam mengatasi tingkat pencemaran air khususnya di Sungai yaitu dengan melakukan dengan usaha yang bersifat preventif, contohnya dengan tidak sembarangan membuang sisa-sisa makanan dan bahan organik sembarangan ke Sungai. Kadar mutu air minum telah ditetapkan dalam PERMENKES 492/2010 terdiri dari standart fisik, standart kimiawi, standart mikrobiologis.

Berdasarkan kasus tersebut, maka peneliti tertarik membuat suatu alat agar dapat digunakan untuk memantau kadar $\mathrm{pH}$, suhu dan warna air sungai yang diolah oleh mikrokontroller arduino uno sehingga dapat di pemerintah untuk menganalisa dalam mengukur tingkat pencemaran terhadap air sungai.

\subsection{Pencemaran Air}

Didalam Undang-undang Republik Indonesia No : 23 tahun 1997 mengenai Pengelolaan Lingkungan Hidup serta Peraturan Pemerintah RI No : 82 tahun 2001 mengenai Pengelolaan kualitas air serta pengendalian kualitas pencemaran air. Yang diartikan dengan dengan masuknya makhluk hidup, zat, energi serta ataupun bahan lainnya ke larutan air oleh aktivitas manusia, yang mengakibatkan mutu air turun hingga ke tingkatan tertentu yang menimbulkan air tidak bisa digunakan sesuai dengan peruntukannya. Pencemaran air terjadi jika ada polutan yang masuk ke dalam air seperti zat kimia, energi dan unsur lainnya sehingga merubah bentuk asli dari air menjadi berubah warna dan mengeluarkan bau yang tidak enak. [1]

Peristiwa pencemaran lingkungan disebut polusi. pemicu terjadinya sebuah pencemaran terhadap air yaitu masuknya makhluk hidup, zat, energi atau komponen lain yang berupa gas, bahan-bahan terlarut dan partikulat ke dalam air yang dapat menyebabkan tingkat kualitas air tercemar sehingga menggangu kegunaan air tersebut. Masukan ini juga sering disebut dengan istilah pencemar (polutan), contohnya buangan limbah cair merupakan buangan yang bersifat rutin. [2]

Menurut Peraturan Menkes RI Nomor 492/MENKES/PER/IV/2010 mengenai Persyaratan kualitas Air terdapat beberapa indikator-indikator penentuan tingkat pencemarannya yang berupa parameter wajib dan parameter tambahan. Dengan kadar maksimum sesuai dengan Permenkes di atas yaitu kadar nilai tertinggi dari setiap nilai-nilai yang ditampilkan sesuai dengan indikator yang diteliti atau di uji coba. Adapun indikator yang akan di teliti penulis meliputi Parameter wajib yaitu kadar $\mathrm{pH}$ air dengan tingkat maksimum yang diizinkan yaitu $6,5-8,5$, suhu air yaitu dengan suhu udara maksimum $\pm 3{ }^{\circ} \mathrm{c}$ dan warna maksimum 15 dengan satuan ukur TCU (True Color Unit)

\subsection{Arduino Uno}

Kemajuan Teknologi Mikrokontroler saat ini sudah sampai pada penggunaan Mikrokontroller dengan berbagai platform open source seperti Arduino Uno. Untuk mengaktifkan Arduino Uno hanya langsung di hubungkan ke komputer dengan kabel USB atau menggunakan adaptor AC ke DC serta menggunakan baterai. Untuk dayanya.

Mikrokontroler merupakan suatu komponen elekronika yang didalamnya sudah terintegrasi dengan I/O Port, RAM, ROM, sehingga dapat digunakan untuk berbagai keperluan kontrol. Mikrokontroler AVR (Advanced versatile RISC) ATmega 32L merupakan low power CMOS Mikrokontroler 8-bit yang dikembangkan oleh Atmel dengan arsitektur RISC (Reduced Instruction Set Computer) sehingga dapat mencapai throughput eksekusi instruksi 1 MIPS (Million Instruction Per Second).[3]

Bentuk Arduino Uno dapat di lihat pada gambar 10. 


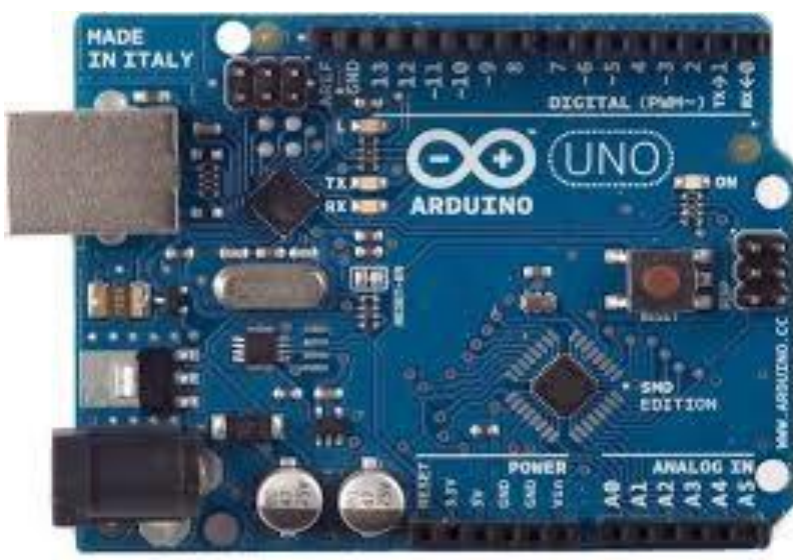

Gambar 1. Arduino Uno

\subsection{Sensor pH Meter}

pH singkatan power of hidrogen, yang digunakan untuk mengukur ion hidrogen yang ada dalam tubuh. Jumlah skala $\mathrm{pH}$ diantara 1 sampai 14, serta 7 dianggap netral. $\mathrm{pH}$ tidak lebih dari 7 dikatakan asam serta larutan $\mathrm{pH}$ yang melebihi dari 7 dasar atau alkali. Sensor $\mathrm{pH}$ air dapat dilihat pada gambar 2.

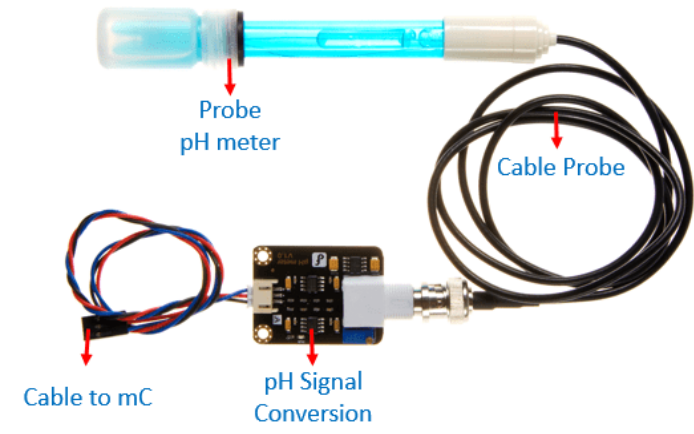

Gambar 2. Sensor pH air

Sebuah alat alat elektoronik yang digunakan untuk mengukur tingkat $\mathrm{pH}$ suatu cairan serta memilik elektroda khusus yang berfungsi untuk mengukur nilai $\mathrm{pH}$ bahan-bahan semi-padat. [4]

\subsection{Sensor Warna TCS230}

Sensor warna yang digunakan peneliti dalam penelitian ini menggunakan Sensor Warna TCS230 dimana Sesnor Warna tersebut memiliki 4 jenis foto dioda yang berbeda, yaitu :

1. 16 dioda dengan filter merah;

2. 16 dioda dengan filter biru;

3. 16 dioda dengan filter hijau;

4. dan 16 dioda tanpa filter.

TCS230 merupakan sebuah photodetektor dengan bentuk kumpulan (array), yang mencakup filter warna merah, hijau dan biru[5] Dimana setiap filter tersebut diatas mampu dalam membaca nilai dengan komposisi RGB. Hasil pembacaan warna-warna tersebut berupa arus yang dikonversi menjadi sebuah frekuensi gelombang kotak dalam bentuk array 8x8 oleh IC TCS230 tersebut.

Sensor warna TCS230 dilihat pada Gambar 3. 


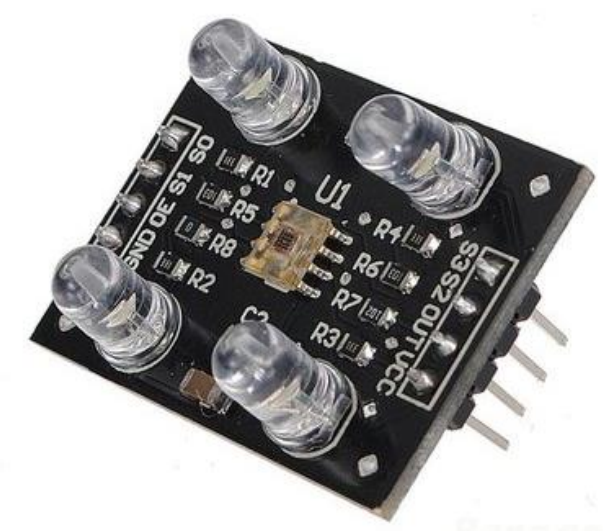

Gambar 3. Sensor Warna TCS230

\subsection{Sensor Suhu Waterproof DS18B20}

Sensor suhu DS18B20 yaitu sensor DS18B20 dengan kemampuan tahan air sensor ini tidak menghasilkan output tegangan, namun menghasilkan pulsa digital. Output yang dikeluarkan langsung di hubungkan ke pin digital yang ada di arduino, tidak menggunakan jalur ADC. Jalur konfigurasi sensor ini hanya melalui satu wire bus dimana hanya dibutuhkan satu jalur data untuk berkomunikasi dengan mikrokontroler.[6] Sensor Suhu Waterproof DC18B20 dapat dilihat pada gambar 4.

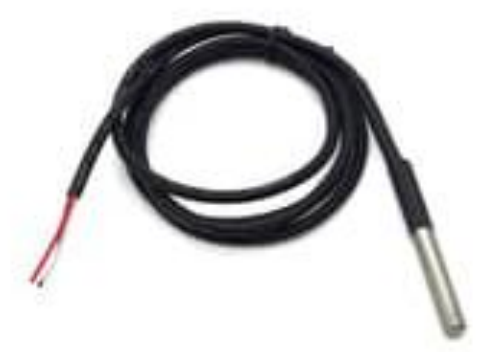

Gambar 4. Sensor Suhu Waterproof

Sensor ini yang terdapat output digital. Sensor suhu DS18B20 ini menghasilkan akurasi pengukuran yang sangat tinggi, dimana pada suhu $-10^{\circ} \mathrm{C}$ sampai $+85^{\circ} \mathrm{C}$. pada umumnya sensor suhu membutuhkan sebuah ADC (analog to digital converter) dan pin port pada mikrokontroler, namun dalam penggunaan sensor Suhu DS18B20 waterproof ini tidak membutuhkan ADC (analog to digital converter) supaya dapat dihubungkan dengan mikrokontroler karna memiliki ADC internal serta hanya membutuhkan 1 wayar saja

\subsection{LCD (Liquid Crystal Display)}

Untuk menyajikan hasil dari setiap sensor-sensor yang bekerja pada Arduino penulis menggunakan LCD (Liquid Crystal Display) 20 X 4 yang merupakan sebuah display yang dalam pengoperasiannya menggunakan sistem dot matriks. "LCD ialah suatu komponen elektronika yang berfungsi untuk menunjukkan suatu hasil keluaran dalam wujud interface (tampilan) informasi. Pada media penampilan LCD memakai kristal cair sebagai penampil data.’[7]

LCD $20 \times 2$ pada umumnya menggunakan 16 pin sebagai kontrolnya, tentu saja akan sangat boros apabila menggunakan 16 pin tersebut. Karena itu, penulis menggunakan driver khusus sehingga LCD dapat dikontrol dengan menggunakan jalur I2C. melalui jalur ini I2C maka LCD dapat dikontrol dengan menggunakan 2 pin saja yaitu SDA dan SCL. Inter Integrated Circuit (I2C) merupakan standar komunikasi serial dua arah menggunakan dua saluran yang didesain khusus untuk mengirim maupun menerima data.[8] 


\section{METODE PENELITIAN}

Sistem yang hendak dirancang pada riset ini merupakan membuat sebuah alat menggunakan sensor $\mathrm{pH}$ air, Sensor warna TCS230, sensor suhu waterproof DS18B20 Berbasis Arduino Uno. Alat ini dibuat agar dapat dipergunakan dalam proses kehidupan sehari-hari khusunya dalam pengujian air Sungai.

\subsection{Rancangan Penelitian}

Dalam pembuatan Alat pemantau kadar $\mathrm{pH}$, Suhu dan Warna pada Air Sungai ini penulis membuat beberapa tahap perancancangan, mulai dari pengambilan data sampai dengan pengolahan yang akan dibuat sehingga hasil outputnya lebih jelas.

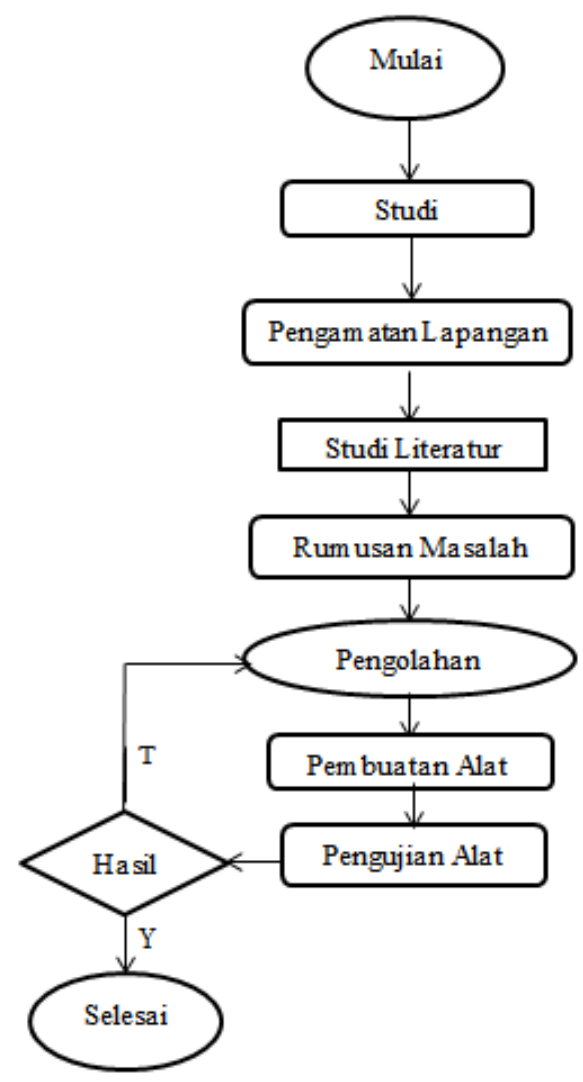

Gambar 5. Rangkaian Penelitian

\subsection{Perancangan Perangkat Keras}

Dalam meringankan perancangan sistem ini maka akan memakai blok diagram untuk tahapan awal dalam proses pembuatannya, dimana blok diagram ini digunakan untuk menampilkan bagaimana cara kerja sistem ini dilakukan secara umum. Dalam perancangan ini disebutkan bahwa semua informasi yang masuk di ukur oleh sensor-sensor yang ada kemudian di proses oleh Arduino Uno serta hasil dari pengujian sensor tersebut akan di tampilkan melalui LCD. Sistem rangkaian dapat dilihat pada gambar dibawah ini :

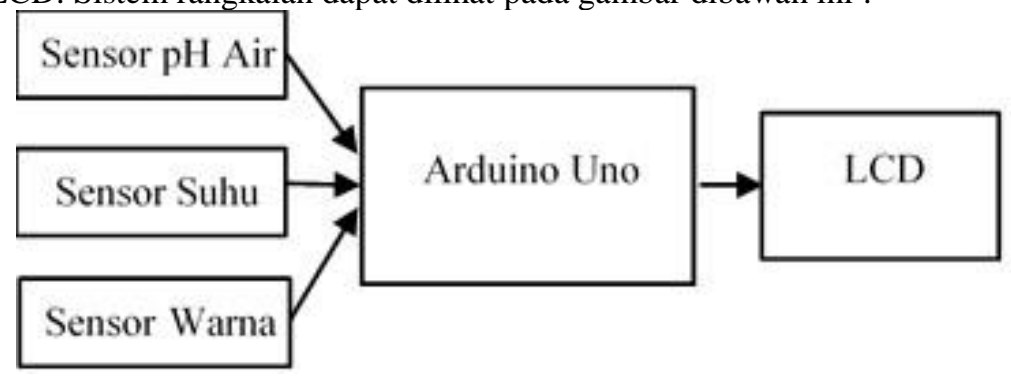

Gambar 6. Blok diagram 


\subsection{Rancangan Rangkaian}

Sistem sensor yang dipakai dalam riset ini menggunakan 1 Sensor pH meter, 1 Sensor Warna TCS230 dan 1 Sensor suhu waterproof DS18B20 serta 1 buah LCD yang digunakan sebagai output atau penampil dari jumlah uji coba terhadap ketiga sensor yang ada. Adapun rangkaian dalam alat ini dapat dilihat pada gambar 7.

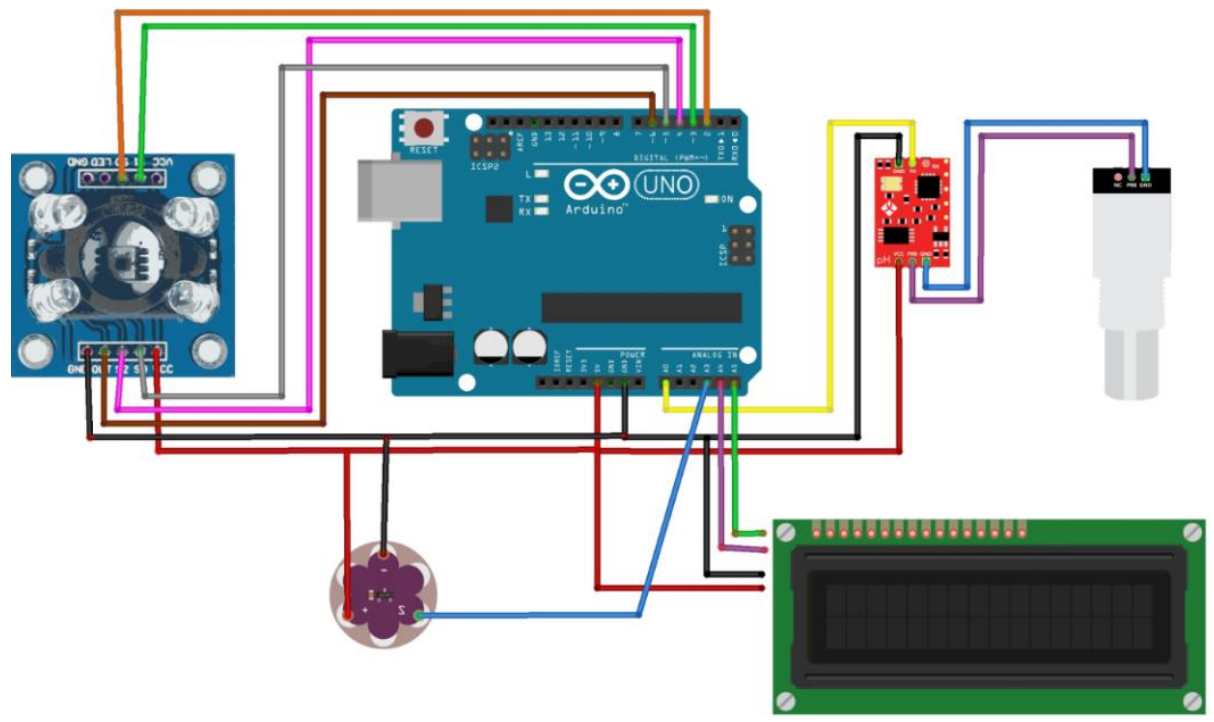

Gambar 7. Rangkaian alat

\subsection{Rangkaian Fisik Alat}

Rangkaian fisik alat pemantau kadar $\mathrm{pH}$, Suhu dan Warna pada air Sungai ini dapat dilihat pada gambar 8

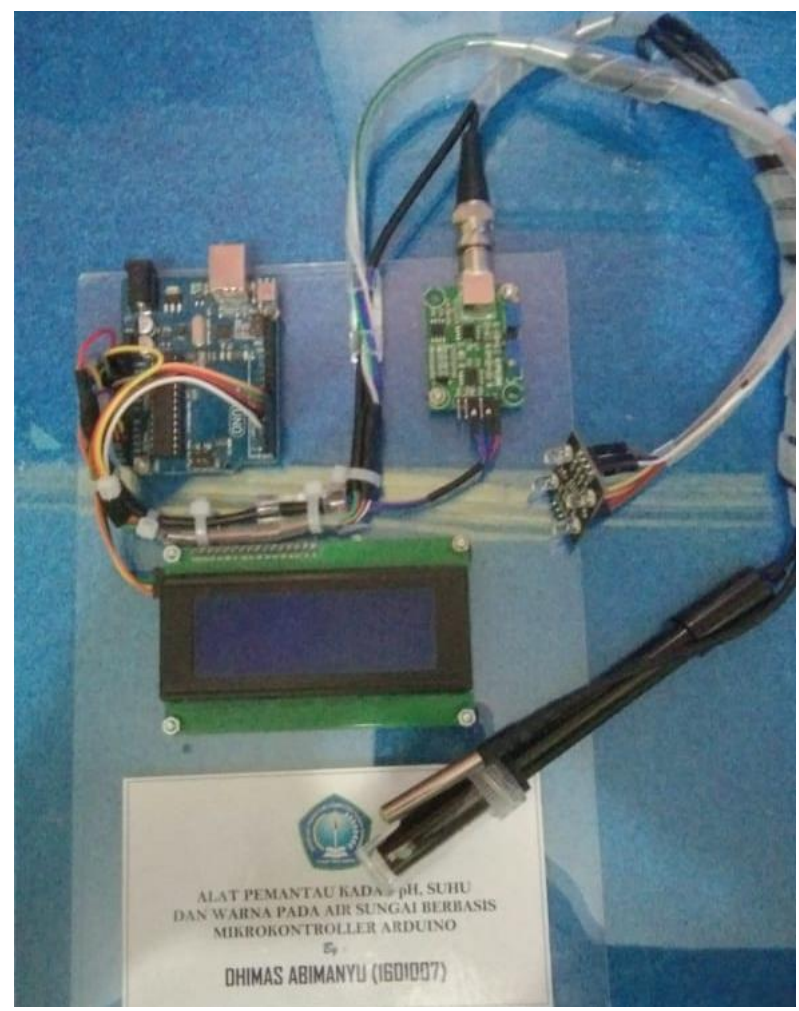

Gambar 8. Bentuk Fisik alat 


\subsection{Cara Kerja Alat}

Cara kerja alat pada penelitian ini adalah sebagai berikut ini :

a. Pada saat Arduino aktifkan yang pertama akan dilakukan yaitu menginisialisasi pada Sensor pH, Sensor Suhu dan Sensor Warna.

b. Lalu Sensor pH, Suhu dan Warna Membaca serta menganalisis data dari setiap Sampel Air yang di teliti dalam jangka waktu tertentu dan menampilkannya ke LCD (Liquid Cristal Display),

c. Saat LCD telah menampilkan Output yang tidak berubah lagi, maka jika tombol Reset di tekan maka Sensor akan kembali mencari Data dan menganalisis data yang Baru Kembali.

\section{HASIL DAN PEMBAHASAN}

Perancangan alat ini bertujuan untuk memberikan kemudahan kepada pemerintah, khususnya yang membidangi perairan untuk memberikan kemudahan dalam menguji tingkat pencemaran air melalui 3 parameter yang di uji sehingga bisa menyampaikan kepada masyarakat umum tentang kalayakan sebuah air sungai untuk digunakan. Untuk mengetehui bahwa alat yang telah dirancang dapat berjalan sesuai dengan kebutuhan dan harapan makan dilakukan uji coba alat baik perangkat keras maupun perangkat lunak.

\subsection{Pengujian Alat}

Dalam pengujian komponen, penulis telah melakukan percobaan dengan beberapa jenis Air Sungai yang ada di Kota Pematangsiantar terkhusus aliran Sungai Bah Bolon Sehingga dapat diketahui nilai pH, Suhu dan Warna pada air Sungai. Berikut ini merupakan hasil validasi data hasil percobaan alat yang telah di buat dapat pada tabel di bawah ini.

Tabel 1. Hasil Uji Coba

\begin{tabular}{|c|c|c|c|c|}
\hline No & Aliran Sungai & Nilai pH & $\begin{array}{l}\text { Nilai } \\
\text { Suhu }\end{array}$ & Warna \\
\hline 1 & $\begin{array}{l}\text { Bah Bolon (samping rumah dinas } \\
\text { Walikota) }\end{array}$ & 7.14 & 24.87 & Hijau \\
\hline 2 & Bah Bolon (Jalan Pematang) & 6.25 & 24.62 & Hijau \\
\hline 3 & Bah Bolon (Rindam) & 7.03 & 24.62 & Hijau \\
\hline
\end{tabular}

Pada tabel diatas dapat dilihat ada 3 sampel percobaan dalam percobaan alat ini, dimana masing-masing titik sampel memiliki nilai yang berbeda-beda. Serta dalam penentuan tingkat pencemarannya tetap mengacu kepada nilai yang dikeluarkan Pemerintah melalui Menteri Kesehatan yang dapat di lihat pada lampiran ini. Dengan demikian dapat dinyatakan alat pemantau yang bekerja sebagai pendeteksi tingkat pencemaran air sungai ini dapat bekerja dengan lancar dan baik untuk pengujian nilai $\mathrm{pH}$, Nilai Suhu dan Warna yang ada. Sehingga dapat digunakan sebagaimana semestinya.

\subsection{Prosedur Sistem Kerja}

Pada tahap pertama uji coba seluruh alat ini penulis menginput daya dari sumber arus listrik sebesar 12 Volt DC menggunakan adaptor 12 Volt DC. Lalu modul Arduino serta sensor tersebut menginisialisasi peralatan dengan sendirinya selama 30 detik sampai dengan 1 menit. Ini berguna untuk menghitung nilai-nilai dari masing-masing sensor. Jika semua sensor selsai mengkonfigurasikan diri, maka sistem akan melaporkan nilai nya yang akan di tampilkan melalui LCD.

Setelah LCD menampilkan hasil dari pembacaan masing-masing sensor jika ingin mendeteksi jenis air berikutnya maka diperlukan menekan tombol reset yang ada pada Arduino maka sensor akan membaca nilainilai yang di deteksi dan menampilkan Kembali ke LCD dengan format teks.

\section{KESIMPULAN}

Setelah dilakukan perancangan dan pembuatan Alat ini, serta telah dilakukan proses pengujian terhadap alat tersebut yang telah di rancang, maka penulis memperoleh kesimpulan bahwa alat pemantai kadar $\mathrm{pH}$, Suhu dan Warna pada air sungai berbasis mikrokontroller Arduino ini dapat dijadikan Pemerintah Khususnya yang menangani Air Sungai untuk menjadi acuan dalam menentukan tingkat pencemaran air yang hasilnya dapat disosialisasikan kepada masyarakat.

Alat ini juga bekerja dengan baik dalam dalam menentukan tingkat pencemaran air berdasarkan 3 indikator tersebut yaitu $\mathrm{pH}$, Suhu dan Warna, dimana sensor-sensor tersebut juga sangat cepat dalam merespon dan 
memproses data sampel yang digunakan untuk uji coba. Pemilihan Mikrokontroller Arduino sangat tepat karena sangat cepat dalam memproses setiap data-data dari sampel- sampel air sungai yang ada.

\section{DAFTAR PUSTAKA}

[1] S. W. Handani, S. Utami, dan D. Kusmira, "Visualisasi pencemaran air menggunakan media animasi infografis," J. Telemat., vol. 10, no. 1, hal. 147-162, 2017, [Daring]. Tersedia pada: http://ejournal.amikompurwokerto.ac.id.

[2] E. Yuliastuti, "Kajian Kualitas Air Sungai Ngringo Karanganyar dalam upaya Pengendalian Pencemaran Air," hal. 127, 2011.

[3] I. G. M. N. Desnanjaya dan I. B. A. I. Iswara, "Trainer Atmega32 Sebagai Media Pelatihan Mikrokontroler Dan Arduino," J. Resist. (Rekayasa Sist. Komputer), vol. 1, no. 1, hal. 55-64, 2018, doi: 10.31598/jurnalresistor.v1i1.266.

[4] I. Nur, "Pengendalian Sirkulasi Dan Pengukuran Ph Air Pada Tambak Udang Berbasis Arduino," Skripsi Univ. Islam Negeri Alauddin Makassar, hal. 13, 2017.

[5] M. Kiftiyah, Santoso, dan Munsyi, "Robot Pendeteksi Warna,” J. Sains dan Inform., vol. Vol.1 No., no. 2, hal. 38-47, 2015.

[6] N. Hidayati, R. Aisuwarya, dan R. E. Putri, "Sistem Kontrol Kestabilan Suhu Penghangat Nasi Menggunakan Metode Fuzzy Logic,” J. Umj, no. November, hal. 1-2, 2017, [Daring]. Tersedia pada: jurnal.umj.ac.id/index.php/semnastek.

[7] F. N. Amin, "Timbangan berbasis arduino dengan output led dan suara," 2016.

[8] Sarmidi dan Sidik Ibnu Rahmat, "Sistem Peringatan Dini Banjir Menggunakan Sensor Ultrasonik Berbasis Arduino Uno," J. Manaj. dan Tek. Inform., vol. 02, no. 01, hal. 181-190, 2018. 